\title{
Movimentos e Matérias da Iniciação à Docência
}

Paola Zordan' 'Universidade Federal do Rio Grande do Sul (UFRGS), Porto Alegre/RS - Brasil

RESUMO - Movimentos e Matérias da Iniciação à Docência. Movimentos junto ao Programa Institucional de Bolsas de Iniciação à Docência (PIBID/ CAPES), desenvolvido junto à Escola Básica com acadêmicos licenciandos, se apresentam aqui junto à perspectiva esquizoanalítica de Deleuze e Guattari. O conceito de matéria é tratado frente sua intrínseca relação com a constituição das disciplinas do conhecimento, enfatizando o dispositivo que envolve o início da atuação de licenciandos em sala de aula. O encontro entre mestres e discípulos configura uma disciplina cuja matéria é constituída na aprendizagem do ensino via uma série de ações, entre as quais se ressalta a criação.

Palavras-chave: Matéria. Disciplina. Escola Básica. Criação.

ABSTRACT - Movements and Matters of Teaching Initiation. Movements by the Institutional Program for Teaching Initiation Scholarships (PIBID/ CAPES), developed at K-12 schools by undergraduates in education, are presented according to the schizoanalytic perspective of Deleuze and Guattari. The concept of matter is addressed by its intrinsic relationship with the constitution of knowledge subjects, emphasizing the device that involves the beginning of the undergraduates' work in the classroom. The encounter between masters and disciples configures a discipline which matter is constituted in the learning of teaching by means of a series of actions, among which creation highlighted.

Keywords: Matter. Discipline. K-12 School. Creation.

Educação \& Realidade, Porto Alegre, v. 40, n. 2, p. 525-547, abr./jun. 2015. 525 http://dx.doi.org/10.1590/2175-623645945 
Movimentos e Matérias da Iniciação à Docência

O presente ensaio pensa a Iniciação à Docência como conceito ampliado, que atravessa amplo rol de experiências dentro com formação de professores e estreias em sala de aula, essas envolvidas na formação acadêmica dos cursos de Licenciatura. Ações do subprojeto Artes Visuais do Programa Institucional de Bolsas de Iniciação a Docência da Coordenação de Aprimoramento de Pessoal de Ensino Superior (PIBID/ CAPES) ${ }^{1}$ da Universidade Federal do Rio Grande do Sul (UFRGS), em sua vigência 2011/2 - 2014/1, se articulam a uma pesquisa dentro do âmbito da Filosofia da Diferença. As considerações aqui apresentadas transcorrem junto a perspectiva esquizoanalítica de Deleuze e Guattari, com referenciais advindos de Spinoza, Nietzsche e Bergson. A vida nas escolas e o pathos de se trabalhar junto à instituição escolar desenham a intensa movimentação da pesquisa, cujos traços acontecem entre a práxis em sala de aula e o estudo de conceitos. Os campos de conhecimento que tais movimentos atravessam implicam matérias, aqui tratadas com a obra conjunta de Gilles Deleuze e Félix Guattari, em especial Mil Platôs, segundo tomo de Capitalismo e Esquizofrenia (1995a; 1995b; 1996a; 1996b; 1997a; 1997b). Ao se deter na concepção dos movimentos e nas convicções que o trabalho com a Iniciação à Docência faz proliferar, ao pesquisar procuramos modos de capturar a vida e dispor as imagens com as quais no acercamos do mistério da matéria no plano, expondo o resultado de descobertas e novas criações, sendo o tema central as ações envolvidas no que vem a qualificar a formação de professores junto a uma educação em vias de se fazer; não mostrando seus feitos. O trabalho procura mostrar a força das fragilidades vividas no desconforto de se estar entre a prática em sala de aula básica e a pesquisa acadêmica stricto sensu, a fim de expressar forças despendidas no dia após dia dentro de escolas. Desse modo, afirma-se uma poética do FRAGIL para operar com linhas maleáveis, ditas fracas, em instituições duras, mostrando ações que acontecem junto a formação de licenciandos. Por isso o texto grifa, como estratégia poética, a repetição dos sufixos nominais das palavras ligadas às ações que criam as multiplicidades, e mesmo as totalizações, as quais movimenta. No intuito de manter uma produção que mistura projetos políticos pedagógicos junto a intervenções artísticas que constituem o material para escrita acadêmica, documenta-se as descobertas conceituais da pesquisa como os projetos de docência desenvolvidos na Escola Básica.

Tudo o que ensinamos pode se tornar uma novidade. Contudo, para descobrir o novo precisa-se de procedimentos que permitam criar junto ao que se descobre. Na educação, um novo campo de estudos vem se configurando junto ao que vem se estabelecendo, além do PIBID Programa Institucional de Bolsas de Iniciação à Docência, no que estamos chamando de Iniciação à Docência. Embora fruto de uma política pública para valorização da carreira docente, pensar a Iniciação à Docência implica o estudo de traçados curriculares, observação de aulas, escuta de professores-alunos, criação de projetos pedagógicos, plane-

526 Educação \& Realidade, Porto Alegre, v. 40, n. 2, p. 525-547, abr./jun. 2015. 
jamento de intervenções no espaço escolar, visitas à escolas, escritura de "diários de bordo" (Oliveira, 2013, p. 121) e formação de professores já inseridos nas redes de ensino (Bello; Uberti, 2013; Tomazetti; Lopes, 2013). A iniciação dos licenciandos antes dos estágios docentes obrigatórios finais para os cursos de Licenciatura, desde 2007, quando data o primeiro edital do PIBID, traz aos estudantes a oportunidade de viverem a realidade escolar ao longo da graduação. A partir do termo Iniciação à Docência, cunhado junto ao Programa da CAPES conceitos aqui se desenvolvem para se pensar a problemática que surge quando acadêmicos licenciandos, independente de qual seja a área de conhecimento, chegam a uma Faculdade de Educação querendo aprender o que fazer e o que, exatamente, afinal, ensinar quando estiverem em sala de aula.

Com a convicção de que ensino e criação não se apartam, esse problema é tratado numa investigação prática que segue a esquizoanálise de Deleuze e Guattari. Por mapear ações em função do que se vive nas escolas, também faz uso do estudo dos dispositivos disciplinares pesquisados por Michel Foucault com as ferramentas teóricas elaboradas pelo professor Deleuze (1996/1985). Seu desafio é mostrar a inserção dos graduandos na Escola Básica para melhor atuar dentro dela, procurando não definir regras fechadas e nem estabelecer um modo de funcionamento ideal (Redin; Stahl; Zordan, 2007). Numa análise entendida como rizomática, pop-filosófica (Deleuze; Guattari, 1995a, p. 34), aqui tratada como "grafia" "decalcomania" disciplinar (Deleuze; Guattari, 1995a, p. 21), listam-se itens capitais para se pensar aquilo que, efetivamente, acontece no espaço pedagógico. Tal espaço extrapola os campos de trabalho estabelecidos dentro do PIBID, sendo circunscrito a uma ampla gama de experiências escolares observadas. Tal perspectiva se dá via a prática como professora na Escola Básica, na supervisão de Estágios Docentes obrigatórios da Licenciatura em Artes Visuais (Zordan, 2008, p. 5) e na implantação e coordenação de subprojeto junto ao PIBID/UFRGS. Atuações nas series iniciais, uma década de ensino de Arte em classes de Artes no Ensino Médio e Fundamental, e

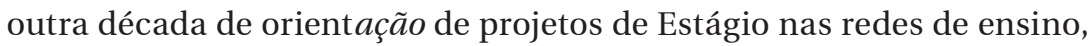
propiciam, dentro do desenho que delineia a pesquisa, uma perspectiva diversificada da Escola Básica. A partir dessas experiências, a Iniciação à Docência é ampliada a toda e qualquer experiência de estreia em sala de aula (Zordan, 2009, p. 55), sendo o trabalho de formação de professores, especialmente nos cursos de Licenciatura, o que, para relacionar com a já estabelecida Iniciação Científica (IC), se institui como ID, independente do aluno pertencer ou não ao quadro de bolsistas do PIBID. Pesquisar junto à coorden ação do subprojeto de Artes Visuais do PIBID/ UFRGS, um dos primeiros projetos institucionais do Programa, endossa análises e conclusões de pesquisas anteriores, desenvolvidas em campos de estágio docente (Zordan, 2008). Paralela às atividades do PIBID, a investigação se insere em uma pesquisa mais ampla, não computada, por questões a seguir colocadas, dentro dos objetivos e atividades pre-

Educação \& Realidade, Porto Alegre, v. 40, n. 2, p. 525-547, abr./jun. 2015. 
Movimentos e Matérias da Iniciação à Docência

vistas para o subprojeto PIBID em suas edições 2011-2014, junto ao qual as considerações aqui traçadas aconteceram.

\section{Uma Outra Concepção de Disciplina}

Propostas de trabalho criadas pelos licenciandos bolsistas foram criadas além do projeto institucional, traçado inicialmente a partir de diagnósticos feitos sobre as realidades escolares examinadas. O dispositivo educacional em análise levou em conta proposições criadas a partir de desejos ${ }^{2}$ diagnosticados nas comunidades porto-alegrenses envolvidas. Com o intuito de licenciandos e professores de escola pensarem juntos como transformar o espaço de convívio, uma apropriação micropolítica (Guattari; Rolnik, 1999, p. 149) da própria instituição escolar foi estabelecida. As disciplinas escolares, segmentadas em áreas de conhecimento, passaram a ser tensionadas junto ao próprio termo disciplina tal como este é tomado no senso comum. Ao perceberem que a palavra tem origem em discípulo e que a tão almejada disciplina a se conseguir numa turma de adolescentes (que prefeririam estar em qualquer outro lugar que não em uma sala de aula) é a postura de quem está aprendendo com o mestre, os licenciandos revisam suas pré-concepções em torno do trabalho docente. Começam a compreender que uma aula que funciona passa longe das técnicas adestradoras, advindas do disciplinamento das formas institucionais modernas e suas imposições para calar (Deleuze, 1988, p. 43). A aula que se deseja envolve o gosto que se tem em torno da matéria. O des-gosto da matéria, não se gostar do que se estuda, gera, por sua vez, a indisciplina. Uma vez que disciplina também é palavra para designar o estudo de uma matéria, essa revisão terminológica impulsiona os acadêmicos a pensar o que vem a ser uma matéria, repensando o conceito de matéria além de suas especificidades estritamente materiais e dos nomes das áreas de conhecimento canônicas. Deleuze, na palestra $O$ ato de criação, ao falar de sua disciplina, a filosofia, ou melhor, uma filosofia muito distinta dos moldes clássicos, trouxe a concepção de "[...] uma disciplina tão criativa, tão inventiva quanto qualquer outra disciplina" (Deleuze, 1987, p. 3). Historicamente, as disciplinas se instituíram junto ao espaço de encontro entre discípulos interessados em aprender uma matéria com um mestre disposto a ensiná-la. Tratamos, então, disciplina como modo de conduzir ensinamentos em torno de uma matéria. Como modo de ação que cria certas ligações, numa maneira singular de tratamento de secções de determinadas matérias, as disciplinas estão implicadas num ethos. Há, portanto, numa dimensão ética da Educação, a busca por um pleno funcionamento do encontro entre professor que gosta da matéria que ensina e os discípulos que querem, por gosto, aprender essa matéria. 


\section{Matéria Matriz}

Aqui, cabe ressaltar as ambiguidades da palavra matéria atentando as disjunções e as sínteses de suas séries de sentido (Deleuze; Guattari, 1996a; Guattari, 1987). Matéria: matriz das coisas, imagens que temos do mundo, recursos da Terra, fonte de matéria-prima, base para produção, corpo, material para criações, documento, monumento, conjunto de conhecimentos, uma disciplina do conhecimento. Em sua multiplicidade de possíveis, passível de tantos nomes, abarca a diferença mostrando as "matérias de expressão" as quais envolvem universos de referência, questões de produção, visibilidades enunciativas, ligações semióticas e as multidões. Conceito que Deleuze e Guattari usam em Mil Platôs para tratar das potências imanentes a um território, matéria de expressão é o que pode ser analisado como a didática inerente a toda e qualquer disciplina. Matéria sempre a se experimentar, exercitar, pesquisar, testar, provar, a didática é a disciplina que trata dos procedimentos a serem operados na multiplicidade de matérias que temos a conhecer. Uma matéria também apresenta formas, conteúdos e substâncias, possuindo códigos e linguagens específicas (Deluze; Guattari, 1995a, p. 55-74; Deleuze; Guattari, 1997b, p. 35). Nos estudos filosóficos estritos à obra de Deleuze, matéria é um conceito advindo dos estudos de Henri Bergson, sendo que, dentro desse referencial, matéria é tudo o que existe em extensão. Para o empirismo de Deleuze e Guattari a matéria constitui o plano estratigráfico do caosmos, um plano extenso formado pelo conjunto de imagens que temos do mundo. O principio da matéria é distensão. O movimento, força que lhe é intrínseca, prolonga-a no espaço. A matéria não tem representação; tudo o que se obtém dos corpos materiais são sensações, vibrações intensas provocadas pelas substâncias incorporais da matéria mesma. Em Matéria e Memória, Bergson mostrou ser inexplicável o processo pelo qual uma sensação se junta à extensão (1999, p. 66), pois não há um termo a ser medido ou um lugar a ser rastreado para saber como um pensamento se atualiza e se produz na matéria. Os objetos percebidos pela visão, pelo tato, na percepção movente, são obras que existem mais de direito do que de fato. Matéria, portanto, se constitui no conteúdo-forma das imagens, dando a ver o espaço externo e real cujo contorno é aquilo que a percepção faz e o que dá sua derradeira nuance. A matéria nada oculta, é o que se expõe (Deleuze, 1999, p. 30) se exibe e se prova.

É a literatura do campo concernente a uma dada disciplina que, historicamente, cria os referenciais que constituem as matérias dos currículos. A prática formalizada, imposta institucionalmente, não impede a existência de disciplinas mais próximas de uma postura ativa necessária à vida da matéria. A concepção de disciplina como policiamento, tendo em vista a conservação das verdades canonizadas que a segmentarizaram, pode dar lugar a disciplinas pensadas como criações junto às matérias nas quais sua existência se detém, tal qual Deleuze, profere: 
Movimentos e Matérias da Iniciação à Docência

Se eu alinhasse todas essas disciplinas que se definem pela sua atividade criadora, diria que há um limite que lhes é comum. O limite que é comum a todas essas séries de invenções, invenções de funções, invenções de blocos de duração/movimento, invenção de conceitos, é o espaço-tempo. Se todas as disciplinas se comunicam entre si, isso se dá no plano daquilo que nunca se destaca por si mesmo, mas que está como que entranhado em toda a disciplina criadora, a saber, a constituição dos espaços-tempos (Deleuze, 1987, p. 4-5).

O único limite é o espaço-tempo imanente às matérias que uma disciplina trata. Seccionar, investigar, cuidar, mostrar as variedades de algumas matérias expressas na Terra circunscreve a tarefa micropolítica dos professores, agentes responsáveis por disciplinas. A disciplina que permeia a prática do ensino, a disciplina da docência par excelence, é a Didática. Uma disciplina criada para dar conta de um mexer-pensar-fazer que pode se ligar a qualquer outra matéria que não as instituídas para a disciplina x ou y nomeadas num programa por diretrizes teóricas e curriculares. Pode se dizer que ao ser a disciplina que trata da construção de uma aula, que pensa modos de expor a matéria e suscitar a aprendizagem, a Didática instaurada junto às matérias é seu agente de transformação.

\section{Dispositivo Didático}

Não cabe dizer, a partir do que se conclui como "aula", que propostas e projetos pedagógicos funcionam, quais performances são as mais adequadas, quais ações propiciam ou dificultam aprendizagens. Os sintomas da realidade observada e os fatos vividos não são relevantes para os movimentos desenvolvidos no presente texto. Não há a intenção de se resolver ou esclarecer os problemas, apenas mostrar o funcionamento de uma práxis pedagógica a fim de valorizar a colaboração entre as partes envolvidas num Programa que aproxima a formação superior de professores à Escola Básica. Essa, primeiramente se configurou uma etapa da formação, sendo seu acesso extenso a segmentos sociais detentores dos códigos (Deleuze; Guattari, 1995b, p. 45) intrínsecos às matérias das áreas de conhecimento privilegiadas nos currículos. Hoje, a Escola Básica se define pela obrigatoriedade e não pelo interesse na aquisição de códigos no curso das matérias, sendo compromisso do Estado garantir a perpetuação da escola e não a existência vital das matérias que podem ser experimentadas. Pela quase inexistência de disciplina, pelo fracasso de procedimentos didáticos e outros problemas, em função do que podemos constatar nos movimentos entre a escola e a universidade, urge se repensar o dispositivo educacional em todas as suas segment ações. O PIBID, ao ser um projeto de instituições universitárias, coordenado por professores-pesquisadores, potencialmente responde aos movimentos que se fazem necessários dentro do dispositivo em questão.

530 Educação \& Realidade, Porto Alegre, v. 40, n. 2, p. 525-547, abr./jun. 2015. 
Tal dispositivo situa a escolaridade obrigatória como ordem incontestável das políticas públicas atuais. As obrigatoriedades produzem doenças no que Deleuze e Guattari chamam Mecanosfera, conceito que aparece em A Geologia da Moral (Quem a Terra pensa que é?), platô 3, para designar um "[...] conjunto de máquinas abstratas e agenciamentos maquínicos" (1995a, p. 86). Traçando um plano cuja consistência "[...] percorrido pelas coisas e signos mais heteróclitos" (Deleuze; Guattari, 1995a, p. 87), a Mecanosfera faz da terra uma matéria muito distinta da matriz que permitiu conceber a provação do conhecimento em termos de gosto. A Mecanosfera dá a ver o funcionamento da produção acelerada de bens e valores que são determinados pelos regimes subjetivos dos "universos de referência" que criam "paisagens existenciais" (Guattari, 1998, p. 29-30). Família, escola, veículos de comunicação, comunidades e outras instituições e redes são "componentes de subjetivação" (Guattari, 1990, p. 19) que funcionam como "placas tectônicas", estratos que fixam modos de produção e séries de sentido, enfim, o mecanosférico do corpo social (Deleuze; Guattari, 1995a, p. 89).

O sincretismo de referenciais imagéticos, a pluralidade de metanarrativas, o emaranhado de teias míticas, forças coletivas, hábitos sociais e outras produções de desejo de um "imaginário global" (Guattari, 1987, p. 83) implicado no que o autor compreende como paisagem existencial, poderia se expressar em qualquer matéria que apaixone alunos e professores. Mesmo quando esses dispositivos favorecem a instituição rígida de uma matéria-disciplina específica, podem funcionar flexivelmente junto a um regime institucional. Ao se considerar a atualização dessa multiplicidade de matérias mecanosféricas em projetos de ensino, obviamente, não se ignora que as ações expressas numa prática disciplinar inserem-se dentro dos regimes semióticos produtivos-econômicos-subjetivos do capitalismo (Deleuze; Guattari, 1996a); envolvendo os campos epistemológicos que sustentaram historicamente o ensino. Na Mecanosfera as matérias estão em relação com espaços culturais diversos, que vão desde as grandes mídias das empresas de telecomunicações, passam por museus, centros culturais, feiras e chegam até as expressões locais, tais como a arte de rua ou a estética doméstica vivida no interior dos lares. Todavia, o que se propõe analisar aqui não são conteúdos imagéticos e formas que fazem parte do que Guattari designou “universos de referência” (1998, p. 77), múltiplas esferas e coisas que tramam subjetividades e dão a ver as paisagens existenciais onde as vidas transcorrem. Aqui, não cabe a análise dos cenários culturais onde uma carga de significações determina o lugar de um sujeito (Guattari, 1987), tampouco o estudo de representações de subjetividade (licencianda-docente-universitário-professorinha de escola), e sim a indicação de forças e vetores de subjetivação que não se restringem ao espaço curricular, escolar e acadêmico, onde as disciplinas didáticas se instituem. 
Movimentos e Matérias da Iniciação à Docência

O que apresentamos segue a ação impessoal do professor junto a sua matéria de modo a se analisar as manifestações, designações e significações dos sentidos (Deleuze, 2000, p. 14-15) que nela se investem. Portanto, essa análise permeia uma investigação de cunho didático sobre possíveis maneiras de se tratar uma matéria, sem nenhuma descrição específica de suas formas, substâncias e conteúdos. Matéria nem sempre expressa em programas curriculares ou listagens de conteúdos específicos, para qual a aprendizagem não tem receita. O que interessa são matérias que criam o território de uma disciplina, atravessado por lições, textos, paixões, exercícios, humores, e propostas. Ações que descrevem o aprendizado didático dispõem afectos, intensidades que acrescentam “novas variedades ao mundo” (Deleuze; Guattari, 1992, p. 227) em projetos de ensino.

Sem descrever nenhum projeto entre os muitos desenvolvidos, nos detemos na movimentação de territórios ou paisagens existenciais (Guattari, 1990; 1998) que se exprimem via agentes implicados na Escola Básica, seja essa implicação dada por trajetória profissional em classes desse ensino, seja no lugar do professor-pesquisador no ensino superior ou ainda seja na perspectiva diversificada dos acadêmicos da Iniciação à Docência. O movimento mecanosférico disposto nesse traçado se articula, por um lado, com a professora-pesquisadora-coordenadora, autoridade disciplinar, autora da esquizoanálise proposta e, por outro lado, pelas produções dos alunos-bolsistas PIBID autorizados a atuarem, junto ao professor supervisor bolsista, na escola. Esses acadêmicos, em estado de iniciação à docência, constituem multiplicidades territoriais que expressam os devires problemáticos do "tornar-se professor". O problema, que numa primeira acepção é sempre o que "fazer em sala de aula" passa, assim que iniciam a pertencer a novos territórios, a "o que vem a ser a matéria que vou ensinar". A visão que cada um expressa é obtida por meio das atividades de ensino, do acompanhamento de projetos e da prática de pesquisa envolvida em toda sua elaboração. Sua atuação se dispõe na formulação dos problemas a partir da documentação de suas criações e interpretação dos acontecimentos vividos em sala de aula, sendo que apresentam diferentes capacidades de atuação dadas por desníveis de experiência e pelas disposições que possuem. Situados entre a Universidade e as intuições escolares, esses agentes ali se colocam em vistas de adquirir um título de Licenciatura, garantia de valor social, mesmo que incerta, que os motiva a galgar etapas e a superar os problemas colocados por cada etapa apresentada pelo território. A intencionalidade de seus atos e a força de suas escolhas fornece a indicação dos caminhos a serem trilhados pela investigação. Não são informantes, mas discípulos em estado de iniciação, ocupados com a colocação e superação de problemas, a última exigindo adaptação de estratégias de acordo com as vicissitudes sofridas em sala de aula. 


\section{Movimentos}

Os movimentos descritos na Iniciação à Docência mostram os devires que percorrem territórios localizáveis tanto na Universidade como nas escolas onde as propostas dos subprojetos específicos são desenvolvidas. Implicam a posição dos alunos da turma que o bolsista acompanha, a presença/ausência dos professores titulares das classes escolhidas para observação, a interação com equipes e gestores das escolas e outras instâncias relacionadas, e, principalmente, os procedimentos didáticos imanentes à disciplina em que irão atuar. Cada bolsista, cada projeto, cada circunstância de Iniciação à Docência cria seu próprio território junto às matérias que lhe são legadas. Tais territórios ganham maior ou menor importância de acordo com as intervenções dos professores-supervisores e bolsistas-licenciandos. Esses, ao invés de se colocarem como sujeitos dentro de um projeto, compõem agenciamentos territoriais que produzem o dispositivo de ensino em questão. Na análise aqui desenvolvida cumprem movimentos involuntários, exigidos pelo Programa na qual estão inseridos. Os agentes estão alheios à existência da pesquisa de sua coordenadora por ineficácia logística entre as atividades e práticas teóricas da pesquisadora-coordenadora e funcionamento do PIBID. A pesquisa não se ocupa de sujeitos do Programa, mas sim dos dispositivos educacionais e modos impessoais pelos quais as matérias são tratadas em sala de aula.

“Conjunto multinear", um dispositivo configura um campo de atualizações cuja variedade de vetores e tensores entre segmentos de diferentes naturezas torna suas linhas constituintes submetidas a "derivações" (Deleuze, 1996, p. 83) de uma razão que produz "tantas bifurcações e ramificações quanto instaurações, tantos desabamentos quanto construções” (Deleuze, 1996, p. 90). Analisar um dispositivo, agenciamento em mutação composto por sedimentações, proliferações, contágios, encontros, fissuras, brechas, curvas de visibilidade, regimes de enunciação e linhas de subjetivação, misturadas e entrecruzadas, é descrever as variações de um campo problemático. "Desenredar as linhas de um dispositivo, em cada caso, é construir um mapa, cartografar, percorrer terras desconhecidas”, enfim, seguir a pragmática deleuzo-foucaultiana de "trabalho no terreno" (Deleuze, 1996, p. 84), o que, devido ao movimento ziguezagueante desse trabalho, pode ser interpretado pelos acometidos de "interpretose" e "significância" (Deleuze; Guattari, 1995b, p. 17-18) como algo bastante confuso.

Os problemas postos pelo terreno da disciplina com a qual a pesquisa se ocupa possuem dois tipos de natureza: conceitual (matéria intensiva em devir) e empírica (material extenso no dado atual). Os problemas conceituais, que se dão junto aos campos epistemológicos da disciplina e suas diferentes linguagens, tendem a ser mal colocados devido ao distanciamento dos agentes frente aos planos de pensamento que envolvem essas intensidades problemáticas. Tais problemas sur- 
Movimentos e Matérias da Iniciação à Docência

gem sob a forma de inquietação, um certo desconforto no plano pré-conceitual estabelecido pelas opiniões do senso comum, de modo que acabam por se configurarem frente a preconceitos que incidem em esferas materialmente estruturadas. Os problemas materiais são aqueles formulados pelos desvios concretos que a disciplina conhece na rotina escolar, tais como falta de materiais para o trabalho pedagógico, espaço inadequado, interrupções administrativas no andamento da aula, violência entre estudantes, evasão, desinteresse generalizado. Junto aos problemas mal colocados, as dificuldades materiais envolvem a falta de interesse pela matéria e resistências em fruir as sensações de seu aprendizado. A diferença de natureza entre os problemas não os separa, pois, assim como a os devires da matéria criam planos de imanência conceituais, os conceitos criados agem sobre o estado concreto das coisas (Deleuze; Guattari, 1992, p. 270). Colocar os problemas disciplinares do ensino implica analisar a formulação de um dispositivo pedagógico cuja máquina recria o sentido do disciplinar. Esse dispositivo opera com a interação de indivíduos, correntes de pensamento, autores, hordas, grupos, instituições, governos e matérias que se dispõem em "linhas de fissura" (Deleuze; Parnet, 1998, p. 147) ou "linhas de fuga" (Deleuze; Guattari, 1996b, p. 95) eminentemente criadoras. As matérias itinerantes desse dispositivo de ensino são atualizadas na população impessoal que coloca seu território em movimento. Pesquisar esse terreno é mapear os modos de ver, modos de inventar, modos de fruir que mostram as maneiras dos professores resolverem os problemas colocados pelas matérias com as quais trabalham, matérias problemáticas que atravessam e constituem o campo em que atuam professores-aprendizes. A indagação, implicada nas forças da matéria que se atualiza na expressividade dos materiais, é saber como se dão as atualizações das virtualidades (Deleuze; Parnet, 1998, p. 173-175) sensíveis na prática pedagógica instituída pela intersecção universidade-escola.

Por meio da anotação dos processos e da pluralidade de registros temos pistas deixadas pela movimentação que se desenha junto a essa práxis. Tais registros primam pela criação em sala de aula, sendo sua documentação o que subsidia o mapeamento da novidade. São documentos nos quais podemos analisar uma possível manifestação de aprendizagem, tendo indícios do que foi absorvido em relação ao que se problematiza, ao que se ensina e ao que pode ser feito numa sala de aula. Esses documentos se compõem dos seguintes itens: (1) os instrumentos da professora-pesquisadora: o diário de bordo de suas incursões escolares, as atas de reuniões entre bolsistas, o quadro de produções e atividades desenvolvidas por cada bolsista, as cartas de intenção justificando interesse no PIBID e históricos escolares dos acadêmicos, relatórios, diário de classe de aulas ministradas, apresentações elaboradas para as formações continuadas de professores nas redes de ensino, sua própria produção intelectual, que inclui textos, apresentações em eventos científicos e palestras; (2) os textos e os trabalhos gráficos ela- 
borados pelos bolsistas, que podem ser pequenas produções textuais a serem usadas em materiais didáticos, a confecção de objetos de aprendizagem e a elaboração de pesquisas individuais sobre a temática dos projetos e os exercícios de escrita inerentes ao andamento da Iniciação à Docência (descrição das escolas escolhidas, entrevistas com coordenadores pedagógicos, diretores e professores, relato das observações, planos de intervenção em sala de aula e relatos das aulas ministradas junto aos professores supervisores bolsistas do PIBID), análises sobre a experiência vivida e a document $a c ̧ a ̃ o$ visual do projeto em toda a sua amplitude de ações, assim como alguns trabalhos de conclusão de curso de acadêmicos ligados ao PIBID; (3) o instrumental didático elaborado coletivamente para ser levado para as aulas (questionários, slides, cartazes, textos, imagens etc.); (4) as produções advindas dos alunos das classes escolares onde propostas do projeto são desenvolvidas; (5) as produções advindas de oficinas, workshops e atividades extraclasse nas escolas onde se desenvolve o PIBID; (6) gravações audiovisuais de várias experiências. Todos esses documentos, embora funcionem como indicadores do que se movimenta no PIBID, não pautam a esquizoanálise aqui proposta. Essa implica atos e atuações descritos adiante, movimentos abertos à participação de todos os agentes, apesar de existirem responsabilidades específicas. Essas especificidades serão apontadas junto às suas descrições. As ações não estão numeradas porque podem ser concomitantes, de modo que não descrevem nenhuma ordem precisa, mesmo que, em certos momentos, algumas pressuponham outras, produzindo o encadeamento a seguir:

Criação: criar, acontecimento vital, é muito mais do que o fazer. Movimento que produz sentido, um “devir-ativo”, a afirmação de Nietzsche (Deleuze, 1976, p. 158), trata-se da ação principal, sem a qual nenhuma outra existiria. Aqui, a criação culmina com a realização do projeto de ensino em sala de aula, mas jamais se esgota na experiência atrelada ao espaço-tempo de sua realização. É um trabalho que permeia todas as outras ações implicadas na vida de quem cria propostas para sala de aula e faz dos fluxos de uma matéria tornar-se algo que valeu a pena ser apre(e)ndido.

Instrumentalização: (movimento desencadeado pelo professor-pesquisador): partir para a aventura de ser professor é singrar um território instável, oceânico. A disciplina é a nau que nos permite atravessar os mares da tempestuosa experiência de se expor em sala de aula para uma turma escolar. Trata-se de saber aprendiz dessa navegação. Um dos instrumentos elaborado é um Guia que reúne tudo aquilo que o iniciante precisa para seguir adiante em sua aventura: bibliografia específica, endereços de sites e instituições de interesse, orientações gerais sobre a condução das aulas, sugestão de roteiros para planos de aula, listas de conteúdos estratificados dentro de sua área de conhecimento, manuais de equipamentos, fichas com instruções técnicas, dicas, tex-

Educação \& Realidade, Porto Alegre, v. 40, n. 2, p. 525-547, abr./jun. 2015. 535 
Movimentos e Matérias da Iniciação à Docência

tos e recados elaborados por acadêmicos de outras edições do PIBID e estagiários de semestres anteriores (Zordan, 2011) e ainda um pequeno glossário de termos. Mais do que isso, essa ação mostra como se adquire e se usa as ferramentas necessárias para o trabalho, indicando os modos de consegui-las.

Experimentação: contato direto com os territórios e a aproximação dos elementos que compõem suas matérias. Experimentar ao que se está disposto em um território é ser sensível aos seus devires, deixar afetar-se por minerais, vegetais, animais, moléculas. Diferente do experimento científico, é a criação feita pelo docente ao experimentar um modo de dar a sua aula e ensinar uma matéria. A experiência de ensino é sempre uma ação junto às matérias que lhe cabem. Ação de professores com alunos, a experiência se dá nos encontros, na prática em sala de aula, nos projetos de ensino e nas produções manual-textuais. Se dá na manipulação, no colocar atenção na matéria, na testagem de técnicas, materiais e possibilidades de ação. Pela experimentação de certos procedimentos, uma matéria se torna disciplinar. As disciplinas desenvolvem modos de ensinar, mostrar, tratar, provar a matéria. Com a experimentação, desenvolve-se um meio para o aprendizado.

Decifração: ação de ler os signos emitidos pelas variações da matéria (Deleuze, 2006, p. 79-80), o que implica aprender sua linguagem e a dominar os códigos que a constituem. Decifrar exige abertura à experiência sensível e o enfrentamento do caos semiótico. Ato da aprendizagem, a decifração requer experiência e o domínio de certos instrumentos. Aprender é captar signos incorporais decifrados nas multiplicidades da matéria que atravessam um fazer.

Observação: visa definir as características do campo de atuação. Ação que apresenta dois vieses de investigação em sala de aula, pois implica aquilo que observamos na escola e na sala de aula, assim como as observações frente às aulas práticas ministradas e o material documentado. Esse movimento também inclui observações em contextos externos, em geral no caso de alunos que cumprem tarefas de outras disciplinas, visitando turmas que não concernem ao Programa. Essas observações permitem a visão de diversos tipos de condução de uma aula. A professora-pesquisadora também faz observações em aulas nas quais atuam os bolsistas. Observar é procurar perspectivas de um território, mas também funciona como inserção gradual do observador que, na medida em que ali se apresenta, também passa a fazer parte de sua paisagem. Há ocasiões em que os acadêmicos são incitados a agir já nas aulas que participam para observar, ou seja, experimentam observações ativas. Mesmo a coordenadora, cuja função é a de observadora passiva da atuação dos acadêmicos, pode, em determinadas situações, intervir com alguma ação, assumindo, alguns dias, a regência de alguma tur$\mathrm{ma}^{3}$. Note-se que o movimento de observação recai nas ações relativas 
ao território da escola, mesmo quando observação documental, tendo em vista os documentos à escola concernirem.

Contextualização: define as paisagens em que o ensino institucionalizado, de caráter obrigatório, acontece, indicando segmentos etários, econômicos e culturais. Contextualizar é fazer um estudo topológico de um campo de atuação: em que lugar tal escola se coloca, a que segmentos da comunidade atende. Também implica uma genealogia de quais culturas a constituem e a análise tipológica do papel que a educação possui em seu meio social. Um levantamento da tipologia (Deleuze, 1976, p. 62) mostra os afectos envolvidos no terreno: as populações que o habitam, os recursos que recebem, os programas curriculares aos quais se submete, as orient ações pedagógicas que o norteiam. Esse movimento visa o levantar os problemas a fim de se conhecer as possibilidades e impossibilidades para se traçar um plano de ação. Sob a perspectiva da professora-pesquisadora-coordenadora, essa ação também faz o levantamento das potencialidades e limitações do corpo disciplinar de seus bolsistas de Iniciação à Docência.

Orientação: orientar é mostrar o oriente, o ponto onde nasce o sol. Em um acontecimento disciplinar, os alunos solicitam orientações do professor sobre a matéria e sobre os exercícios que os ajudam a aprendê-la. Os acadêmicos são orientados tanto pela pesquisadora-coordenadora como pelo professor-supervisor-bolsista na escola, junto ao qual, o projeto, para funcionar, precisa estar em consonância. Quem orienta indica caminhos, atentando-os para os perigos e obstáculos e atestando o lado onde o sol nasce. Ação que oferece o olhar panorâmico da supervisão e estima os pontos cardeais dos territórios por onde transitam os professores-alunos. A orientação ajuda o futuro professor avaliar as possibilidades logísticas de sua atuação e intervir para o melhor funcionamento de suas estratégias.

Investigação: movimento de pesquisar que extrapola a pesquisa do coordenador e caracteriza todo desenvolvimento de um projeto. Trata-se de ir atrás de mais perspectivas sobre a matéria, revirar o contexto, procurar pelo que está fora do regular colocado na disciplina. Ação que busca material didático, em especial na pesquisa de referências, implica seguir os temas, conteúdos e substâncias de interesse. Investigar também é fazer consultas bibliográficas e aprofundar as leituras sobre aquilo que surge para ser trabalhado em sala de aula. Exploração de materiais, de textos, de técnicas de feitura, testa a viabilidade de aplicação destes. Tal movimento também investiga a familiaridade dos alunos com os instrumentos, suportes, elementos específicos de cada matéria.

Elaboração: ação que constrói o traçado de um projeto de ensino ou simples plano de intervenção em sala de aula no contexto de um projeto mais amplo. Trata-se de pensar o que fazer na prática e como programar 
Movimentos e Matérias da Iniciação à Docência

as atividades a serem propostas nas aulas, o que exige adequação à realidade encontrada (número de aulas a serem dadas, horário do período, perfil dos alunos, exigências da escola, etc.). Uma descrição sistematizada e cronológica (mesmo em projetos de curta duração,como no caso das intervenções pedagógicas de Iniciação à Docência) não pressupõe que se siga um modelo com um roteiro, mas obriga à definição do que vai se fazer, por quais motivos, de que maneira e com quais recursos e materiais. Elaborar um plano é criar um mapa para orientar a ação dos professores e dos alunos junto a uma matéria. Durante seu andamento, um plano pode precisar de uma adaptação em suas coordenadas para melhor funcionar frente às instabilidades apresentadas pelo território.

Demonstração ou explicação: ação que cria maneiras de mostrar as características e o funcionamento de uma matéria. Implica os tratamentos aos dados materiais que lhe dão substância, o domínio de técnicas ou modos de fazer com que as secções e cortes na matéria tenham sentido prático, assim como o conhecimento das especificidades de cada disciplina e contextos culturais das manifestações envolvidas. Expressa a atuação didática, o modo pelo qual o professor coloca a matéria (na mesa, no quadro, nos slides, no discurso) para os alunos. Explicar o que essa matéria vem a ser, mostrando suas peculiaridades, demonstrando como se funciona, se usa, se faz... são movimentos de tornar viva a matéria a ser aprendida.

Improvisação: inspiração súbita frente aos imprevistos e contratempos de toda e qualquer ordem, inclusive dentro das explicações. Ação que requer inventividade e flexibilidade frente ao inesperado e permite ao planejado se reinventar. Trata-se de encontrar maneiras para vencer as resistências, modos de lidar com a evasão (não apenas física) e com a invasão de coisas que interrompem e atrapalham o andamento previsto para as aulas.

Apreciação: fruição das coisas criadas, abertura às sensações emitidas pela matéria e sobre o que dela se produz. Ação pedagógica que dá valor ao que a matéria expressa expõe dentro do projeto. Apreciar envolve os diferentes modos pelos quais as pessoas se relacionam com as mais variadas manifestações socioculturais, o que independe da aquisição dos códigos da linguagem da matéria para designar os elementos apreciados em suas mais diferentes características formais, funcionais e econômicas.

Avaliação: processo analítico constante, que trata de compreender como as ações estão se desenvolvendo, não para julgar o que está bom ou não, mas para entender como funcionam suas dinâmicas, intensidades, gradações afectivas, nuances sensoriais. Avaliar acontece junto aos afetos, no encontro de corpos e nas matérias que se disciplinam. Avalia-se para sentir a movimentação invisível, os desejos que guiam suas li- 
nhas, as zonas de calmaria, os pontos de choque, as quebras drásticas, as fusões. A avaliação, imbricada ou não com a orientação, não acontece sem o lado de Fora (Deleuze, 1988, p. 126-127), Outro de que extrai o olhar exterior que a situa (Deleuze, 2000, p. 319). Implica, sempre, em tomar o dispositivo pelo reverso. Antes de marcar uma diferença, ver normalidades e abominações, a avaliação existe como ação sobre o funcionamento de um dispositivo, satélite que captura a imagem de um território e cria recortes de planos de pensamento, para melhor os estudar. A avaliação é o movimento constante implicado na atualização das virtualidades do pensamento. Em função de obrigar o movimento ao Outro, configura a força mais atuante do dispositivo em questão.

\begin{abstract}
Pertencemos a dispositivos e neles agimos. À novidade de um dispositivo em relação aos que os precedem chamamos atualidade do dispositivo, a nossa atualidade. O novo é o atual. $\mathrm{O}$ atual não é o que somos, mas aquilo em que nos vamos tornando, aquilo que somos em devir, quer dizer, o Outro, o nosso devir-outro (Deleuze, 1996, p. 92-93).
\end{abstract}

Os movimentos acima descritos, acolhendo a previsibilidade das performances e as surpresas de suas composições, perpassam as ações de Iniciação à Docência e a implicação destas com planos conceituais da atualidade. Traçar as linhas criadas por essa movimentação é documentar o dispositivo das matérias disciplinares junto as quais cada docente cria seu território de atuação. A esquizoanálise aqui proposta configura uma maneira de tratarmos os problemas colocados no território aberto, de fronteiras maleáveis, da Educação. Mutação de crenças e condutas, participar do PIBID, para um acadêmico, é se deixar impregnar pelas experiências, refazer-se mesmo que dentro de um curso, mesmo na rigidez de princípios implicada numa formação. Tornar-se professor, não apenas formado institucionalmente, mas transformar-se, ser in-formado, em devir, nunca pronto, feito, mas aberto às novidades. Desviar-se do Eterno "para apreender o novo" (Deleuze, 1996, p. 91), o que requer uma abertura sensível ao novo e a criação de uma didática intempestiva, composta pelas matérias aprendidas e por ações que permitem que ela seja ensinada.

\title{
Provar as Provas
}

Não há como se tornar professor sem passar por inevitáveis provações. Provas de mestria que obrigam o iniciante na docência a enfrentar campos problemáticos, ultrapassar obstáculos, criar estratégias, inventar modos para manter viva a alma da matéria que quer ensinar, entre tantas outras coisas. As provações em sala de aula são acontecimentos que testam a vontade de potência (Deleuze, 1976, p. 40) daquele que gozará da responsabilidade e alegria de ser professor, preparar aulas, ensinar e pesquisar uma matéria e desenvolvê-la junto à colegas e alunos. Aprender a ser professor é extrair a qualidade extemporânea dos devires 
de uma matéria, não para torná-la “objeto de conhecimento”, mas para experimentar as sensações incorporais que fazem da matéria a expressão de um pensamento.

Matéria virtual que se produz extensa, documento, registro concreto de um modo de pensar que desenha os devires da matéria. Uma matéria de expressão que configura o traçado de projetos de ensino dos acadêmicos que iniciam sua atuação nas redes de ensino. $\mathrm{O}$ desenho que dá a ver singularidades e regularidades de um dispositivo educacional observa a formação de arborescências ou segmentos duros e seguir por rizomas, experimentando linhas criadoras não axiais (Deleuze; Guattari, 1995b, p. 12-17). A partir de todos documentos, em especial nos que registram a criação de projetos pedagógicos, temos uma variedade de maneiras das matérias serem ensinadas e variações do modo pelo qual algumas matérias são efetivadas disciplinarmente. Matérias que transitam dentro do espaço curricular aberto por onde incidem as propostas do PIBID, mas que, entretanto, não se furtando a seguir modelos, procuraram procedências. Embora o trabalho aqui previsto envolva a orientação, sua realização não pretende fornecer vias seguras, corretas e ideais do que seja ensinar uma matéria. Há uma demanda muito grande, por parte de professores dos mais diversos segmentos, para que os especialistas de diversas áreas de ensino mostrem o que devem fazer. Ao se observar as variações daquilo que se pode fazer é possível questionar aquilo que as disciplinas já fazem quando ficam detidas em conteúdos e formulações didáticas que sedimentam certas práticas e elegem determinadas "matérias" como constituintes dos programas curriculares. Ao se guiar pelos devires de disciplinas que continuamente se inventam, essa investigação junto ao PIBID defende como, mesmo no espaço institucional regular, a criação nas multiplicidades da matéria se torna possível.

Trabalhando em cima de todas as dificuldades históricas das divisões das disciplinas nas escolas, os bolsistas se dividem assistindo as aulas a fim de entender como essas acontecem na escola, entrevistando funcionários, alunos e alguns professores que se dispõem a conversar. A presente investigação esquizoanalítica estuda a realidade escolar para problematizar as inconsistências metodológicas nas propostas observadas, o uso de imagens desprovido de sentido em sala de aula, a canonização de informações distantes do contexto dos alunos e por fim a eleição dos bons trabalhos sob critérios de um equivocado e excludente conceito de capricho. Sobre tais fatos, outro estudo, mais genealógico do que esquizo-analítico, articulados com a pesquisa mais ampla, discutem os sintomas das segmentaridades adoecidas no dispositivo da Iniciação à Docência na Escola Básica (Zordan; Sthal, 2011). Projetos pedagógicos com o intuito de fazer com que os alunos se sintam parte da escola, deixando nela seu recado, criando suas marcas, construindo algo diferente nos espaços de uso comum, foram executados junto ao PIBID em distintas etapas do currículo, em diferentes séries interme- 
diárias do Ensino Fundamental, no Ensino Médio e no Ensino Médio Técnico. Projetos de intervenção no espaço escolar consistem em uma ação social, uma estratégia micropolítica, a qual pode criar uma espécie de cisão entre o constructo educacional e os devires das matérias. Tal fissura ocorre especialmente quando seus saberes oscilam entre sua instituição como disciplina pertencente ao currículo da Escola Básica e os fragmentados universos de referência trazidos pelo público escolar. Afirmando uma vontade que extrapola essa profusão de referências e os modos de subjetivação dominantes (Guattari, 1998, p. 80), que arrebanham todos para um modo de olhar estreito e cerceador, buscamos sair da contemplação de imagens canônicas (Zordan, 2012, p. 97) e textos consagrados para contrapor estes à criação de novos modos de vida, em especial e sempre que possível, dentro das escolas.

O que se afirma nessa intensa movimentação acontece no desejo de seguir trabalhando com apropriações produtivas e sustentáveis por parte de agentes cuja vida dentro da escola é inevitável. Como os demais ambientes institucionais contemporâneos, a forma de escola na qual atuamos hoje tem suas origens na sociedade disciplinar estudada por Foucault (Cruz; Freitas, 2011). Com a intenção de dispor de outro modo de pensar a gênese do sentido disciplinar e buscar outra maneira de operar institucionalmente, o que se estabeleceu como meta explicitada no subprojeto formal ${ }^{4}$ é que a escola se torne um espaço-tempo de fruição, pensamento e criação. As manifestações dos alunos, mesmo as depredatórias e agressivas, são trabalhadas como potencialidades e não como motivo para apartá-los do aprendizado de matérias. A aprendizagem proporcionada nas disciplinas, pelo encontro entre mestre e discípulos com o desejo de explorar uma matéria, é a condição sine qua non da escola existir.

\section{Ensino EnSignos}

Junto ao estudo de Hjelmslev, por uma linguística de fluxos e uma imanência algébrica da linguagem, Deleuze e Guattari, ao postularem a linguagem como sistema de signos articulados, observam que nesse sistema o código digital abstrai as imagens expressas, sendo que toda a linguagem funciona como uma espécie de perda das possibilidades de expressão de uma matéria. A linguagem se restringe à transmissão de palavra como função ordenadora/composta de expressões assemióticas, sem significação, sem necessidade de interpretação. Mesmo consistindo num regime heterogêneo de signos assemilógicos, pautada por funções assignificantes em variações contínua, com esses autores entendemos que um sistema de figuras (não-signos) constitui um conglomerado de fatos não-linguísticos, físicos, psicossociais; entidade de partes que se condicionam reciprocamente e criam imagens de pensamento, ou seja, matérias. De algum modo o que se costuma dizer linguagem imagética não comunica signos com função de informar, pois não

Educação \& Realidade, Porto Alegre, v. 40, n. 2, p. 525-547, abr./jun. 2015. 
Movimentos e Matérias da Iniciação à Docência

se trata de uma família de enunciados que somente classifica, traduz, calcula. Uma linguagem é constituída a partir de fatores intrínsecos a si mesma, funcionando por meio de constantes universais que a definem como sistema homogêneo, de modo que só pode ser estudada cientificamente sob as condições de um sistema padronizado, ou seja, via estabelecimento de códigos. Como os códigos demandam das formas, apresentam variações de natureza e um funcionamento efetivo nos territórios cuja consistência se dá com a matéria. As populações implicam códigos que exprimem os movimentos territoriais, operando por descodific ação e sobrecodific $a c ̧ a \tilde{o}$, sendo que encontramos matérias mais ou menos codificadas, sobrecodificadas e decodificadas de acordo com os processos semióticos que nelas foram operados. Por sobrecodificação entendemos o centramento, a totalização, a unific $a c ̧ a \tilde{o} o$, a integração, a hierarquização e a finalização que a linguagem opera na matéria que constitui os territórios ou paisagens existenciais. A individuação intensa e a diferença múltipla das matérias de expressão consistem num ser unívoco que se estende a toda matéria e tem como figura a Terra, o que leva o pesquisador afirmar aquilo que o devir da Terra nega: o imperativo do texto e as explicações que os acadêmicos encontram para falar dela. Composição verbal que interpela o corpo obrigando-o a se fazer discurso, o texto documenta processos de aprendizagem que tanto se dão a ver por meio de palavras quanto por coisas (matéria para qual temos imagens) para dizer como o homem trata a Terra e que imagens extraem dela para compreender suas forças inteligivelmente. Sobrecodificada, a Terra vira Mecanosfera e as disciplinas, enquanto sobrecodificação das matérias imanentes à Terra, tornam-se sobrecodificações da própria matéria.

Entretanto, uma disciplina, qualquer disciplina pode propor espaços para experimentações da matéria que lhe é intrínseca. Observamos isso em diversas ações, nos mais diferentes tipos de escolas, em $n$ incidências documentadas pelas escolas (não apenas as cadastradas no PIBID) pelas quais se circulou. Ao se envolver com a criação de intervenções efêmeras em algumas escolas, estaduais e municipais e instalações permanentes no Colégio de Aplicação da UFRGS, reafirma-se os resultados de pesquisas anteriores ao constatar a importância da comunidade escolar, especialmente o corpo discente, intervir pedagogicamente nos espaços de convívio. As marcas que os corpos inferem no patrimônio comum afirmam as singularidades, o que fortalece o pertencimento à comunidades e desejo de se estar na Escola. Projetos pedagógicos em salas de aula das redes de ensino de Porto Alegre expressam movimentos pelos quais se aprende como, em instituições de ensino como a Escola e a Universidade, as forças dos afectos presentes na matéria se fazem valer.

Os temas do grupo que movimentou o projeto versaram sobre a história da cidade de Porto Alegre, tolerância religiosa, patrimônio cultural, arte de rua, diversidade étnica, multiplicidades de gênero e trans- 
gêneros, variações de gosto e por fim a simbologia de culturas que não apenas as europeias. Numa pesquisa que tem como objeto principal o corpo, aparentemente uma esquizoanálise das atividades do PIBID não se relacionava com os amores, os fluxos sanguíneos, a água, a terra, as cores, as sensações, as mulheres, o jogo interativo, a feminilidade, a hysteria da pintura e a escrita que pautaram a pesquisa mais ampla (Zordan, 2014), em especial os interesses e temas escolhidos pelos mestrandos que, alheios às atividades do PIBID, dela participaram. Tanto pelo pensamento da Diferença de Gilles Deleuze como pela escolha de temas, por vezes tomados como desprezíveis, é preciso mostrar o embate desta perspectiva dionisíaca, matriarcal, maníaca, com as prescrições educacionais estritamente normativas. Desse modo fomos também conduzidos a estudar a genealogia da moral, o masoquismo institucional e o pathos trágico. As paixões que nos são destinadas, por mais assustadoras que sejam, mostram as experiências adquiridas pelos corpos, instrumentos e aparelhos que antes de qualquer discurso, vivem para fazer da vida matéria de expressão. Uma paixão acontece quando algo fatalmente arrebata o corpo de tal modo que o corpo, afectado, padecendo daquilo que lhe é estranho, nunca mais se torne o mesmo. Tornar-se professor ou professora nos exercícios de ensino que envolvem a Iniciação à Docência é criar um novo e nunca definitivo corpo, cujo caráter experimental leva os acadêmicos a reinventarem práticas e discursos arraigados ao campo educacional.

Sem a pretensão de argumentar sobre os prós e contras de determinados procedimentos didáticos, cria-se a substancialização de um adjetivo, fazendo do FRAGIL um substantivo comum, digno de nossas criações efêmeras no espaço institucional, especialmente as forças despendidas no dia após dia dentro de escolas. A poética FRAGIL, cuja descrição das intervenções, instalações e performances o presente ensaio não comporta, surge como afirmação de uma produção, que hoje se desqualifica dentro dos moldes vigentes em busca da afirmação da arte e da poesia. Tudo o que se quer foge das argumentações e afirma uma paixão. Afirma-se o processo ao invés do resultado, a paisagem movente no lugar da conclusão, a marca ao invés da representação. Junto aos conceitos filosóficos dos autores da filosofia da Diferença, tenta-se mostrar um traçado rizomático, testar grafias provisórias, extrair dos fatos movimentos, marcar existência com a criação de um ambiente alegre e profícuo, embora bombardeado e fragilizado. Entre tantos acontecimentos, o FRAGIL aparece como a inexistência de uma obra e a própria desvalorização de um modo não produtivista de pesquisa, pois, eventos com as comunidades, tempo despendido nas escolas e na gestão dentro de um projeto como o PIBID, o qual constitui uma das principais políticas públicas para o fortalecimento da docência brasileira (Bello; Uberti, 2013; Tomazetti; Lopes, 2013), não computam nada na produção qualificada do pesquisador, o que torna o trabalho com a escola básica frágil enquanto produção válida de novos conhecimentos.

Educação \& Realidade, Porto Alegre, v. 40, n. 2, p. 525-547, abr./jun. 2015. 
Movimentos e Matérias da Iniciação à Docência

Em seu recorte ligado à Iniciação à Docência, mais do que averiguar uma documentação específica em torno das produções que obtivemos junto ao PIBID, a pesquisa trata da vida transcorrida em sala de aulas (Zordan, 2014). O que aqui se escreve só e possível porque vivemos, em vários lugares e ocupando posições distintas, a escola em todos os seus níveis e nas mais diversas instâncias (Zordan, 2011, p. 95). Se não fossem os pesquisadores professores marcados pela atuação junto às etapas iniciais da educação, talvez pensar a formação docente, a escola e métodos de ensino seria impossível. Tais experiências na Escola Básica nos levam a questionar a educação escolar compulsória a qual a população está submetida, sendo que, de modo mais abrangente, os problemas incitados a partir dos movimentos descritos na Iniciação à Docência levam a pontos nevrálgicos da educação contemporânea, em suas implicações ecológicas, estéticas e psíquicas.

O encontro entre mestres e discípulos configura uma disciplina cuja matéria se constitui na práxis teórica do ensino, cuja aprendizagem acontece, entre várias ações, via criações, elaborações, instrumentalização, investigação, contextualização, explicações e avaliações. Tal encontro pode ativar desejos e trocas produtivas que potencializam agentes advindos de todos os segmentos do dispositivo educacional implicados na Iniciação à Docência. Licenciandos que se empolgam com a vida nas escolas, escolares interessados em diversas matérias, professores de classe traçando projetos plenos de sentido para seus alunos, professores-pesquisadores trazendo questões de instituições que abarcam a grande maioria da população: tudo isso foi possível de ser documentado junto aos movimentos aqui descritos. Por fim, a compulsoriedade da educação escolar é questionável na medida em que o envolvimento com as matérias não advém de escolhas interessadas e sim de meras obrigações instituídas, deslocando o papel de propagação de saberes e conhecimentos da escola, fundada junto às disciplinas do conhecimento, para a formação de cidadania via ações comunitárias que podem mais tender ao assistencialismo do que criar projetos para aprendizagem de matérias. Não podemos mudar o mundo e encher as escolas apenas com os que desejam o que nela se tenta ensinar, mas é possível transformar a paisagem dentro da escola modificando as ações que trazem as matérias para dentro das salas de aula.

Recebido em 26 de março de 2014 Aprovado em 14 de setembro de 2014

\section{Notas}

1 O Programa Institucional de Bolsas de Iniciação à Docência da Coordenação de Aperfeiçoamento de Pessoal de Nível Superior (CAPES), fundação vinculada ao Ministério da Educação (MEC), surge em 2007 como política pública para valorização da carreira docente através de projetos institucionais. Primeiramente contemplou Universidades Federais, após, foram aberto editais com possibilidade de inscrição para todas instituições de ensino superior e

544 Educação \& Realidade, Porto Alegre, v. 40, n. 2, p. 525-547, abr./jun. 2015. 
Institutos Federais. O projeto de cada instituição comporta subprojetos das áreas de conhecimento e subprojetos interdisciplinares coordenados por professores do seu quadro funcional. Dirigido aos cursos de Licenciatura, o foco do PIBID é o aprimoramento da formação docente dos licenciandos junto a realidade escolar. Com verba de custeio que subsidia atividades dos futuros docentes em escolas básicas, o programa se desenvolve em parceria com as redes de ensino, promovendo diálogo entre a Escola Básica e as instituições que formam os bolsistas estudantes. Professoras e professores da rede de ensino, com a função de supervisores que acompanham os bolsistas nas atividades dentro das escolas, também participam do PIBID recebendo bolsas. A bibliografia sobre os resultados do projeto e demais pesquisas em torno do assunto são incipientes, requerendo mais atenção da comunidade acadêmica sobre o assunto. Disponível em: <http://www.capes.gov.br/educacao-basica/ capespibid>.

2 Desejo, numa perspectiva esquizoanalítica, configura o modo de produção vital que movimenta o próprio corpo social junto a todos devires (animais, vegetais, minerais) do território (nomos). Um fluxo desejante percorre um território nas linhas traçadas pelos povos, tribos, hordas e bandos, os quais, ao se estabelecerem em determinados locais, vem constituir as cidades muradas e posteriormente os Estados. Ao contrário da concepção psicanalítica de desejo como obturação das faltas e chistes inconscientes (em termos de formações) temos um desejo como simples forma expressiva, motriz desenfreada de produção e não uma produção desejante sobre o que, a priori, não se tem. Cf.: Deleuze; O anti-Édipo: capitalismo e esquizofrenia. Lisboa: Assírio e Alvim, 1996a.

3 Frente à imensa dificuldade, manifesta por alguns licenciandos, em ministrar aulas em determinadas turmas de series intermediárias, a professora doutora há tempos não atuando em classes escolares precisou, com consentimento das escolas, assumir por alguns períodos tais turmas impossíveis para compreender a dificuldade vividas por seus bolsistas e estagiários junto as mesmas. Sair da zona de conforto do que antigamente chamaríamos cátedra, se colocar na linha de frente que é o trabalho na Escola Básica, enfrentar agressividade e descaso dos adolescentes, improvisar, rearticular os planos de ensino perante o que funciona, na hora, em classe, atuando e estando na mesma posição que o licenciando aprendiz, foi vital para uma orientação efetiva e aprimoramento do processo de iniciação à docência.

4 As metas descritas no subprojeto Artes Visuais/PIBID/UFRGS, em vigor entre 2011 e 2013, eram o desenvolvimento de projetos pedagógicos de âmbito gráfico, pictórico, plástico e visual, em sala de aula e espaços de educação continuada (como oficinas), que envolvessem a comunidade escolar, com ênfase no patrimônio artístico local e obras de arte contemporâneas; a pesquisa sobre telas e monumentos históricos com a intenção de valorizar, divulgar e educar a comunidade quanto a importância de sua preservação; a criação de material pedagógico para ser acessados pelo corpo docente das escolas onde os projetos foram desenvolvidos; mediação e fruição de obras de arte e valorização do fazer artístico, do estudo de contextos sócios culturais e compreensão da emergência de novas linguagens e tecnologias; continuidade das ações interdisciplinares com subprojetos de Letras, Biologia e Ciências Socio-históricas, em especial os iniciados na edição anterior do PIBID/UFRGS e a divulgação das pesquisas e resultados da prática pedagógica em eventos. Disponível em: <http://www. ufrgs.br/pibid/>. 


\section{Referências}

BELLO, Samuel; UBERTI, Luciane (Org.). Iniciação à Docência: articulações entre ensino e pesquisa. v. 1. São Leopoldo: Oikos, 2013.

BERGSON, Henri. Matéria e Memória. Tradução de Paulo Neves. São Paulo: Martins Fontes, 1999.

CRUZ, Priscila A. S.; FREITAS, Silvane A. de. Disciplina, Controle Social e Educação Escolar: um breve estudo à luz do pensamento de Michel Foucault. Revista do Laboratório de Estudos da Violência, Marília, n. 7, p. 36-49, jun. 2011.

DELEUZE, Gilles. Nietzsche e a Filosofia. Tradução de Edmundo Fernandes Dias e Ruth Joffily. Rio de Janeiro: Ed. Rio, 1976.

DELEUZE, Gilles. O Ato de Criação. 1987. Disponível em: <http://ladcor.files. wordpress.com/2013/06/gilles-deleuze-o-ato-de-criao.pdf>. Acesso em: 01 mar. 2013.

DELEUZE, Gilles. Foucault. Tradução de Claudia Sant’Anna Martins. São Paulo: Brasiliense, 1988

DELEUZE, Gilles. O que é um dispositivo. Tradução de Edmundo Cordeiro. In: DELEUZE, Gilles. O Mistério de Ariana. Lisboa: Passagens, 1996. P. 85-100.

DELEUZE, Gilles. Bergsonismo. Tradução de Luiz Orlandi. São Paulo, Ed.34, 1999.

DELEUZE, Gilles. Lógica do Sentido. Tradução de Luiz Roberto Salinas Fortes. São Paulo: Perspectiva, 2000.

DELEUZE, Gilles. Proust e os Signos. Tradução de Antonio Carlos Piquet e Roberto Machado. Rio de Janeiro: Forense Universitária, 2006.

DELEUZE, Gilles; GUATTARI, Félix. O Que é a Filosofia? Tradução de Bento Prado Jr. e Alberto Alonso Muñoz. Rio de Janeiro: Ed. 34, 1992.

DELEUZE, Gilles; GUATTARI, Félix. Mil Platôs: capitalismo e esquizofrenia. v. 1. Tradução de Aurélio Guerra Neto e Celia Pinto Costa. São Paulo: Ed. 34, 1995a. DELEUZE, Gilles; GUATTARI, Félix. Mil Platôs: capitalismo e esquizofrenia. v. 2. Tradução de Ana Lúcia Oliveira e Lúcia Leão. São Paulo: Ed. 34, 1995b.

DELEUZE, Gilles; GUATTARI, Félix. O Anti-Édipo: capitalismo e esquizofrenia. Tradução de Joana Moraes Varela e Manuel Maria Carvalho. Lisboa: Assírio e Alvim, 1996a.

DELEUZE, Gilles; GUATTARI, Félix. Mil Platôs: capitalismo e esquizofrenia. v. 3. Tradução de Aurélio Guerra Neto, Ana Lúcia de Oliveira, Lúcia Claudia Leão e Suely Rolnik. São Paulo: Ed. 34, 1996b.

DELEUZE, Gilles; GUATTARI, Félix. Mil Platôs: capitalismo e esquizofrenia. v. 4. Tradução de Suely Rolnik. São Paulo: Ed. 34, 1997a.

DELEUZE, Gilles; GUATTARI, Félix. Mil Platôs: capitalismo e esquizofrenia. v. 5. Tradução de Peter Pál Pelbart e Janice Caiaf. São Paulo: Ed. 34, 1997b.

DELEUZE, Gilles; PARNET, Claire. Diálogos. Tradução de Eloísa Araújo Ribeiro. São Paulo: Editora Escuta, 1998.

GUATTARI, Félix. Revolução Molecular: pulsações políticas do desejo. São Paulo: editora Brasiliense, 1987.

GUATTARI, Félix. As Três Ecologias. Tradução de Maria Cristina Bittencourt. Campinas: Papirus, 1990.

546 Educação \& Realidade, Porto Alegre, v. 40, n. 2, p. 525-547, abr./jun. 2015. 
GUATTARI, Félix. Caosmose, um Novo Paradigma Estético. Tradução de Ana Lúcia de Oliveira e Lúcia Claudia Leão. Rio de Janeiro: Ed. 34, 1998.

GUATTARI, Felix; ROLNIK, Suely. Micropolítica: cartografias do desejo. Petrópolis: Vozes, 1999.

OLIVEIRA, Marilda. Sobre o PIBID Artes Visuais da UFSM. In: TOMAZETTI, Elisete; LOPES, Anemari Luersen Vieira. PIBID-UFSM: experiências e aprendizagens. v. 2. São Leopoldo: Oikos, 2013. P. 113-124.

TOMAZETTI, Elisete; LOPES, Anemari Luersen Vieira. PIBID-UFSM: experiências e aprendizagens. v. 2. São Leopoldo: Oikos, 2013.

ZORDAN, Paola. Potências das Artes Visuais em Sala de Aula (Relatório Final de Pesquisa). Porto Alegre: FACED/UFRGS, 2008. $184 \mathrm{f}$.

ZORDAN, Paola. Ensinar. In: AQUINO, Julio; CORAZZA, Sandra (Org.). Abecedário: educação da diferença. Campinas: Papirus, 2009. P. 55-59.

ZORDAN, Paola (Org.). Iniciação à Docência em Artes Visuais: guia e experiências. 1. ed. São Leopoldo: Oikos, 2011. 144 p.

ZORDAN, Paola. Iniciação à Docência em Artes Visuais: problematizações em torno de discursos. In: ICLE, Gilberto (Org.). Pedagogia da Arte: entre-lugares da escola. v. 2. 1. ed. Porto Alegre: UFRGS, 2012. P. 83-107.

ZORDAN, Paola. Paixões da Diferença: liberação de humores artísticos (Relatório Final de Pesquisa). Porto Alegre: FACED/UFRGS, 2014. $331 \mathrm{f}$.

ZORDAN, Paola; REDIN, Mayra; STAHL, Cassiano. PesquiZação no Ensino das Artes visuais. In: CONGRESSO INTERNACIONAL DE EDUCAÇÃO: PEDAGOGIA (ENTRE) LUGARES E SABERES, 5., 2007, São Leopoldo. Anais... São Leopoldo, 2007. P. 1-10.

ZORDAN, Paola; STAHL, Cassiano. Sala de Aula, Torturas e Suplícios: perspectivas da arte. Caderno Pedagógico, Lajeado, v. 8, p. 4, 2011. (Impresso).

Paola Zordan é mestre e doutora em Educação, bacharel em Desenho e licenciada em Educação Artística pela UFRGS. Na mesma instituição é professora do Programa de Pós-graduação em Educação, atuando entre a Educação e as Artes Visuais.

E-mail: paola.zordan@ufrgs.br 